Harald Bache-Wiig

Universitetet i Oslo

\title{
Olaf Malms historie. Om en skjebnefigur i Vilhelm Bergsøes roman Fra Piazza del Popolo
}

\author{
The story of Olaf Malm: About a person of destiny \\ in Vilhelm Bergsøe’s novel Fra Piazza del Popolo
}

\begin{abstract}
In translation the title of this article would be: "The story of Olaf Malm: About a person of destiny in Vilhelm Bergsøe's novel Fra Piazza del Popolo". The novel was published in 1867, and in many editions it is subtitled: "a cycle of short stories". But this article is meant to show the reader that one of the stories, told by a character called "The old artist", in itself can be read as a completed work of literature. The story of a young, Norwegian sculptor is meticulously composed, weaving a tissue of entangled threads of destiny. All his works are demolished, yet the protagonist finally appears as a creator of divine art. This is also an accomplishment both of the narrator: the old artist, and Bergsøe himself.
\end{abstract}

Key words: Sculptor, clay, plaster, marble, resurrection

Nøkkelord: Billedhogger, leire, gips, marmor, gjenoppstandelse

Det kom som en stor overraskelse på det lesende publikum i København da den unge naturforskeren Vilhelm Bergsøe, født 1835, i 1867 debuterte som skjønnlitterær forfatter med boka Fra Piazza del Popolo. Livsbilleder samlede i Rom. Den var på 699 sider og sjangeren «livsbilleder» var noe uklar. I seinere utgaver ble undertittelen endret til Novelle-Cyklus.

I alle fall: Med ett knusende unntak, nemlig Clemens Petersens anmeldelse i den nasjonalliberale avisa Fodrelandet fem, seks uker etter utgivelsen ${ }^{1}$, var mottakelsen svært imøtekommende. Litteraturforskeren Paul V. Rubow omtaler i 1948 boka som «den danske Litteraturs maaske ejendommeligste, i alt fald mest populære Fiktionsverk» (Rubow 1948: 10), og den fikk tallrike gjenopptrykk og også oversettelser til både tysk og svensk.

${ }^{1}$ Anmeldelsen er gjengitt i sin helhet i Rubow (1948: 16-32). Slik lyder først setning i Petersens anmeldelse: «Errare humanum est, men når Fejltagelsen bliver syvhundre Sider stor, begynder den rigtignok at blive umenneskelig» (Ibid.: 16). 
Boka inneholder en lang rekke livshistorier. Gjennom tre bind er de arrangert som en kjede av muntlige fortellinger. Spørsmålet om disse fortellingenes rolle og funksjon innenfor en felles rammefortelling, blir ikke tatt opp her. Som tittelen på denne artikkelen gir signal om, vil jeg i det følgende se nærmere på én historie i boka, kalt «Malms Historie». Den blir fortalt av en skikkelse som blir omtalt som «Den gamle Kunstner». Den er interessant fordi den gir et originalt perspektiv på selve kunstfeltet i Europa slik det var under utvikling da boka til Bergsøe ble til. Ikke minst er Europa i 1860-åra inne i en brytningstid når det gjelder synet på den litterære fortellingen. Kan en slik fortelling komme på høyde med den nimbus som den gang var tilkjent ikke minst billedhuggere med røtter i antikken? Er det noe i kunsten som kan gjøre mennesker til noe mer enn bare kjøtt og blod, og da med andel i det evige? Den gamle kunstnerens vitneprov, hans fortelling av livshistorien til en ung kunstner fra norske Telemark, Olaf Malm, er et godt indisium på en ny bevissthet om kunstens mening og kraft også innenfor fortellekunsten.

Historiene i boka er fortalt av personer som alle sokner til det miljøet som i 1860 ble forent under paraplyen «Den skandinaviske Forening» i Roma. Mange av medlemmene, Jonas Lie kalte dem «Kunstens Trækfuglskare» (1871)², fikk gjerne innrettet en bolig i Roma. Dem vi hører om i boka, har sin ukentlige møteplass på et slags stortorv rett innenfor den gamle byporten, kalt folkeplassen: «Piazza del Popolo». Unge Bergsøe var selv en del av dette miljøet i 1862/1863. Det må likevel understrekes at både fortellerne og alt de forteller om, er ment å utgjøre et helhetlig, fiktivt kunstunivers uten klar referanse til navn og hendelser hentet fra virkeligheten.

I denne perioden var den romerske pavestaten politisk et slags fremmedlegeme; ennå ikke innlemmet i Italia som samlet nasjonalstat. For skandinavene kunne byen kjennes både som et fengsel og som et beskyttet fristed. Prisgitt all denne ambivalens og usikkerhet kunne det oppstå behov for å fortelle hverandre historier - litt som i Boccaccios Dekameronen (1353). Men hos Bergsøe er det ikke angst for pest og død innenfor en storby som utløser frykten, men tvert om alt det skremmende som ulmer utenfor Roma, bl.a. røverbander med grisk sans for fanger og løsepenger.

Historien om Olaf Malm blir, som nevnt, fortalt av «Den gamle Kunstner» (i boka siden kalt «den Gamle») ${ }^{3}$. Han er billedhogger og er en slags grand old man innenfor miljøet av unge lærlinger, forskere og kunstskjønnere som i bokas åpning er samlet rundt obelisken på Piazza del Popolo. Et slags anslag i romanen er et veddemål mellom en ung, norsk kunstkritiker og en dansk lege, Henrik Verner.

\footnotetext{
${ }^{2}$ Denne karakteristikken av skandinaver i Roma finner vi i diktet «Mortensgilde i Rom» skrevet til Den skandinaviske Forenings feiring av Mortensdagen 11. november 1871. Diktet er tatt med i bind. X av J. Lie: Samlede Digterverker (1920-1921: 526-527).

${ }^{3}$ Selv om ingen av bokas fortellere var ment å henspille direkte på personer som den gang var del av Den skandinaviske Forening i Roma, hadde nok «Den gamle kunstner» en ganske tydelig modell i billedhuggeren C.F. Holbech (1811-1880). Jf. Rubow (1948: 36).
} 
Verner vil trenge seg forbi vokterne som ikke lar noen komme ut av byen, og han lover stor gevinst til nordmannen hvis han ikke er tilbake på piazzaen innen kl. 12 samme kveld. Mens gjengen venter, får de høre en danske fortelle Verners forhistorie som legestudent i den danske hovedstad, koplet nært til året 1853 da en fatal kolera-epidemi rammet København. Kl. 12.00 dundrer kirkeklokken i Peterskirken og nordmannen kan rope: «Der brast Norges Rige af din Hånd, min Herre!» . (Fin ironisk snert her: I 1814 tapte Danmark Norge til det svenske riket).

Veddemålet var tapt. Men Henrik Verner klarer seg og er i høy grad levende både i syklusens midtre og avsluttende del ${ }^{5}$. Og dagen etter sitter den Gamle på en av de fire løvene på obelisken ${ }^{6}$ og kan fortelle historien om en nordmann som i utgangspunktet er framstilt som alt annet enn en taper. For 30 år siden dukket en ukjent mann opp hos den danske og svensk-norske konsul i Roma. Han er høy og bred, med hvit telemarkskofte, mørke knebukser og lærbelte. Bare et mulig brev til en viss Olaf Malm interesserer ham. Han får brevet, sier «Takk!» og forsvinner deretter ut døra.

Den Gamle ble imponert av en slik likefram atferd hos en skandinav som nettopp er kommet til Roma. Han mener at personer som er få av ord, gjerne er mer i gjerning. Dette var en dyd også den bereiste norsk-dansken Ludvig Holberg (1684-1754) mente folk fra Norge kunne smykke seg med: handlekraft som følge av besluttsomhet, uten sans for overflødig snikk-snakk.

\section{Møter mellom Malm og fortelleren, i Roma og ved Nemisjøen}

Fortellerens inntrykk av Malm ved møtet hos konsulen blir bekreftet når han dagen etter treffer Malm i det store studioet nordmannen nettopp har leid. Malms planer er store, ja, grandiose. Han ønsker å lage en statue av gigantene som stormer Olympen. Og han viser stolt fram et slags selvoppfunnet kjeglespill som består i å slynge stein ut gjennom et lite hull i veggen. Den Gamle mener den fysiske ferdigheten som Malm her demonstrerer, må skyldes studium av den greske skulpturen Diskoskasteren, laget av billedkunstneren Myron ca. 450 år før Kristus. Malm har ikke kjennskap til

${ }^{4}$ Bergsøe (1877: 79). Replikken er hentet fra en velkjent episode i Snorre Sturlasons Heimskringla, sagaen om Olav Tryggvason. Replikken er bueskytter Einars svar på kong Olavs spørsmål: «Hva brast så høyt?».

${ }^{5}$ Henrik Verner, i andre del omtalt som Henry Vernon, viser seg i bokas siste del å være sønn av Olaf Malm og Sigrid, jenta Malm forelsket seg i hjemme i Telemark og treffer igjen i Roma. Men denne koplingen er løst fundert i romanen. P.V. Rubow (jf. Note 1) mener «det er højst usandsynligt at Malm oprindelig har været ment som Henrys fader» (s. 15).

${ }^{6}$ I boka Rom - pladsernes by: 40 pladser og deres sevordigheder (1996) opplyser forfatteren Ole Askov Ask at «blandt skandinaviske guldalderkunstnere var det tradition, at deres ophold i Rom blev innledet med en ridetur på en av løverne» (s. 178). Den Gamle agerer som Malm! 
denne skulpturen, men setter pris på å bli spurt. Kast med diskosplate viser jo at også «de gamle» visste om spillet Kav, en guttelek Malm mener alle kjenner til i Telemark.

Alt tyder på at navnet på dette spillet er funnet på av Bergsøe. Men et liknende spill fantes og er beskrevet i Bernt Støylens Norske Barnerim og Leikar (1899) under navnet Skothella (side 105). Det gikk ut på å kaste stein mot en oppstilt skiferhelle, og å få poeng for å velte, treffe eller å komme nærmest steinen. I Malms versjon er det ikke nok å treffe en skiferhelle. En hel pyramide av murstein må bygges opp, som så skal knuses av en tung stein kastet fra langt hold. Noe han selv demonstrerer med stor kraft.

Neste gang den Gamle treffer på Malm, sitter han dyster ved bredden av Nemisjøen, en innsjø oppe i et fjell-landskap nord for Roma. Han er tilsynelatende like knust som den Kav-pyramide han selv har bygd opp ca. $50 \mathrm{~m}$ bortenfor stedet han sitter. Og nå får den Gamle hans forhistorie.

Som fattig bondegutt satt i tjeneste hos en rik skog- og sagbrukseier i hjembygda, har Olaf fått sitt kall som kunster av Sigrid, dattera til denne storbonden, og hun er lys og fager. En søndag lager han en bjørn av leirklumper han finner ved elva. Sigrid dukker opp, setter seg og følger arbeidet hans. Det ender med at hun tilbyr ham et kyss for å få bjørnen i eie. Denne byttehandelen inngår han gjerne, og bjørnen blir hennes. Deretter blir han med henne hjem. Alle roser ham, og mens Sigrid ser på, lager han også - på oppfordring av en fremmed fra Christiania - et barnehode i leire. «Et englehode», sier den fremmede (Bergsøe 1877: 95). Men mest med Sigrids trekk, mener han selv. Slik blir han oppdaget, kommer i lære i Christiania, vinner priser og får stort stipend. Turen til Roma gjør han mest til fots.

Alt som skjer med ham siden, kan knyttes til dette «barnekysset». Sikkert også den ferske drømmen han kan fortelle den gamle om. I den får han se en hulder som stiger opp av tåkene over Nemisjøen. Huldra lar ham vite at for hver stein han klarer å kaste helt over sjøen, vil han makte å skape et verk som er like godt og feilfritt som dem på sjøens bunn. Men dersom han ikke lenger når fram til den andre sida, vil alt være tapt og alle verkene hans vil bli glemt.

På mange måter opptrer vel huldra her som en utvandret, norrøn norne, en skjebnegudinne, som kunngjør hva slags skjebnetråder som vil bestemme livsløpet til Olaf Malm. Etter å ha hørt den Gamle fortelle om et flytende gullslott som, ifølge sagnhistorisk stoff fra romertida, sank til bunns i Nemisjøen, setter han seg selv på prøve ved å slynge stein ut over sjøen. Og, mot alle odds: Tre av dem lander i steinene på motsatt bredd. Så tar han en fjerde, mye tyngre stein, men den lander i sjøen med et plask. «Det sprang Noget i min Arm», som han sier (Bergsøe 1877: 99)7. Senene i armen er overanstrengt, og den Gamle lar ham en lang tid bo i sin egen leilighet som pleiepasient. De er nå blitt gode venner.

\footnotetext{
${ }^{7}$ Lesere vil her naturligvis bli påmint om sitatet fra Heimskringla, jf. note 4.
} 
Den videre fortelling om Malm går gjennom tre tydelige faser som alle henter gjenlyd fra episoden ved Nemisjøen ${ }^{8}$. Helt mot slutten av den tredje fasen, før Olaf Malms skjebne definitivt blir vendt mot en tragisk farget utgang, oppsøker den Gamle Malm i verkstedet hans. Ved synet av den ferdig oppstilte statuen der, opplever han sannheten i en gammel tese:

«Leret er Liv, Gibsen Død, men Marmoret Opstandelsen» (Ibid.: 139).

\section{Leire}

Som utøvende kunstner i Roma går Olaf Malm igjennom tre stadier som kan knyttes til denne treenigheten i fullbyrdelsen av et kunstverk og av et kall som skapende kunstner. Etter en lang, passiv periode kommer han helt brått i gang med en skulptur formet i leire. Det er en romersk faun som i jublende glede holder opp en guttesønn med små, butte horn. Den Gamle ser straks at det er et helstøpt kunstverk som ved videre arbeid bare kan bli enda vakrere. Likevel nevner han at den høyre armen kanskje er litt i korteste laget. Mange andre får se utkastet, og Malm får ry som lovende mester stikk motsatt hans tidligere, dårlige rykte. Men når den Gamle så kommer tilbake etter et langt sommerfravær, har Malm revet ned statuen.

Men dette hans første kunstverk struttet altså opprinnelig av liv, og grunnen viser seg å være en liten hilsen fra Sigrid i et brev fra Malms mor. Som den Gamle sier: Det var Sigrid som hadde skapt Malms faun. All den seinere forkludringen skyldtes alle slags, ofte motstridende, forslag til «forbedringer» som byens kunstskjønnere, selv om de var begeistret, hadde utsatt Malm for. Det er altså datidas ulike oppfatninger om hva som er god kunst som her blir fatalt styrende for den unge kunstnerspire fra norske Telemark. Den Gamle heller selv mot en måte å vurdere på som ikke lar seg styre av avisdebatter, og mener at det alltid kan skilles klart mellom skitt og kanel. Og han vinner en debatt med en ung, norsk kunstkritiker som mener at all kritikk er berettiget. Tvert om, ofte kan unge talenter og deres verker bli ødelagt av nedsettende omtaler fra ukvalifiserte synsere/forståsegpåere.

\section{Gips}

En type kunstkritikk som tilsynelatende var av et annet slag enn den estetiske, var den religiøse. Den blir avgjørende for Malms neste utkast til en fullført statue. Men først kommer han i en voldsom - men ikke voldelig - konflikt med en annen,

${ }^{8}$ Det er all grunn til å nevne her at i norrøn mytologi var det tre gudinner som bestemmer over menneskers skjebne: Urd (fortid), Verdande (nåtid) og Skuld (framtid) og som er til stede hver gang et menneske fødes (Nettutave av Store norske leksikon: http://snl.no/norner). 
skandinavisk kunstnerspire. Nemlig svensken Dahlqvist som med et nytt stipend kan overta det store verkstedet til Malm. Malm må flytte til et som er langt mindre siden han ikke har fătt sitt eget stipend fornyet. I et fornemt selskap hører han den belevne kunstrivalen rakke ned på ham, og, pang! velter han oppstilte blomstervaser, skjeller ut Dahlqvist og forsvinner. En skandale!

Når den Gamle dukker opp hos ham noen dager seinere, har han et nytt, mektig verk stilt opp på kavalettoen. Nemlig en naken Akilles som med hjelm og skjold lagt ned på siden, grubler på hevn over Agamemnon som har stjålet hans elskede frille Breiseis fra ham. Malm er tydelig blitt mer oppdatert på klassikken, og han henter denne gang sitt motiv fra greske legender og ikke fra romerske folkesagn. Dahlqvist, derimot, dyrker det søtladne, lettvinte og frir uhemmet til Romas frankofile borgerskap.

Men en ny skikkelse dukker opp, Svingberg, en dansk kunstkritiker som ifølge den Gamle ser seg selv som representant for den eneste rette lære. Og som profet gjør han straks suksess i fremmed land, dvs. i de fornemme kretser i Roma som har vendt Malm ryggen. Den Gamle tror denne isoleringen har vært til stort gagn for Malm og oppsøker ham fordi Akilles-statuen i gips nå skal være klar for å bli støpt i jern. Han vil gratulere. I stedet ser han til sin forbløffelse at Svingberg blir lukket inn i Malms verksted, og fra utsiden får han høre et særs oppbyggelig foredrag.

Svingberg hamrer løs både på forestillinger om storhet i gresk og romersk kunst og på katolisismen som med vievann, virak og røkelse har drømt seg bort fra det sanne Gudsbilde, som er Kristus. For Svingberg er det bare den hellige kunst, den kristne framtidskunst, som lik kirkenes gotiske spir peker opp mot himmelen. Mennesker framstilt helt uten klær, som Malms Akilles, peker bakover til antikkens hedenskap og barbari.

Til denne preken hører den Gamle Malms dype, rolige stemme si «Amen!» Den troskyldige telemarking lar latt seg lokke til å betrakte alt han har oppnådd som kunstner som et syndefall. I den Gamles øyne framstår predikant Svingberg som en djevelsk slange. Men Malm har latt seg omvende og vil ikke lenger ha noe med den Gamle å gjøre. Han blir sparket ut av døra til Malms verksted, der den herlige Akilles står forsømt, tørr og oppsprukket, en gipsstatue som aldri kan vekkes til live igjen.

\section{Marmor}

Også Svingberg har lagt den Gamle for hat og spotter hans kunst i hvert nummer av en København-avis som den gang ble lest av mange dansker i Roma'. Men, «heldigvis», så kommer koleraen til Roma og Svingberg tar med seg Malm til Na-

\footnotetext{
${ }^{9}$ Kunne ha vært avisa Foedrelandet, som fra 1834 utkom som et nasjonal-liberalt alternativ til
} den kongevennlige avisa Dagen (1803-1843). 
poli. Der dør predikant Svingberg brått av den smitten han flyktet fra, og i Romas skandinaviske kretser dør også læren hans. Men hvor er Malm blitt av?

Høsten kommer, og på en iskald vandring som ender på arenaen i Colosseum, får den Gamle øye på en sovende, avmagret uteligger som ligger inntullet i en fillete, romersk kappe. Lyset fra lampen over et madonnabilde gjør ansiktet brått synlig, og den Gamle utbryter: «Herre Jesus! Er det Dig, Malm?» (121). Den Gamle har ikke tatt feil, og han kan nå gi Malm rikelig med mat og husly, og dagen etter også noen brev hentet hos konsulen. Malm mottar brevene med et jubelskrik, og snart er han ute og leier seg et stort verksted - han er altså gjenoppstått som ambisiøs kunstner. Men hvorfor?

Snart viser det seg at det er vakre Sigrid som igjen har blåst nytt, skapende liv inn i fattiggutten som jobbet på gården til den rike faren hennes. Og nå - sikkert med sin ankomst meldt av moren i et av brevene til Malm - dukker hun fysisk opp i Roma sammen med faren og moren. Det tar litt tid før de møtes. I mellomtiden smisker Dahlqvist seg med flid innpå Sigrid. Men så får Malm og Sigrid oppleve gjenforening foran et åpent ildsted som gir minnelser om alt de kommer fra. «Det var som to lykkelige Børn, der legede med hinanden» sier den Gamle (130). Sigrid setter seg ved et piano, og så synger de hver sine vers av en gammel, mollstemt, norsk folkemelodi. Den handler om gutten som var dratt til fjerne land for å vinne heder og rikdom, jenta som lengter, og som til sist hører en lur i fjellet. Det er gutten som har vendt tilbake.

Jentas far, herr Olaisen, har null sans for kunst, men er klok på mammon. Når den Gamle kan fortelle ham at når Malm ikke gjorde ferdig de to arbeidene han fikk så mye skryt for, så var det fordi han ville vente til prisen falt på marmor. Da skjønner Olaisen at Malm er en klok mann og betaler gjerne for produksjonen av en ny statue, denne gang sluttført i marmor. Og allerede tre dager seinere har Malm gjort klart et utkast i leire. Det er en Psyke, og den Gamle er strålende fornøyd: Psyke står med et klede som er sklidd ned mens hun strekker armene ut etter den flyktende Amor. Figuren utstråler overalt levende harmoni, med strenghet og renhet i formen. Selveste Bertel Thorvaldsen dukker også opp, betrakter Psyke-figuren med et blikk som «syntes at trænge lige ind i figurens inderste Kjerne», vender seg mot Malm og sier: «De har en smuk Fremtid for Dem» (135).

Også faren er fornøyd; og jenta i leire har «ta’e mig Fan, min Datters Ansigt» (130), sier han. Og Sigrid stiller gjerne opp som modell for hodet mens verket blir videreført i gips. Etter ivrig arbeid, han «lo og sang» $(138)^{10}$ gjennom både vinter, vår og en halv sommer, får Malm statuen hogd ferdig og er klar for å levere den. Den gamle har vært borte fra Roma en stund, men oppsøker Malm i verkstedet

${ }^{10}$ Antakelig en liten hilsen til Henrik Ibsens dikt Terje Vigen, publisert 1862. I annen strofe hører vi om Terje som en forløst person, befridd for sin onde skjebne. «Han lo og sang». 
og får se det ferdige kunstverket. Og der står Psyke, bundet til den kalde marmor, men likevel fri og lett, «ved Kunstens Magt løst fra dette, beredt til, i Foryngelens Øieblik at flyve med til de salige Guders Himmel» (139).

\section{Slangen}

Med dette storslåtte kunstverket fullført, har ikke bare dette lykkekastet, men også de to foregående landet på den andre siden av Nemi-sjøen. Ingen ting har vært forgjeves, Huldra/Nornen har, så langt, så godt, spådd sant om Malms skjebne. Men så åpner han et brev den gamle har tatt med fra konsulatet, leser det, blir kritthvit i ansiktet og slynger med enorm kraft en hammer mot hodet på statuen. Og dermed har han vunnet i Kav, knust sitt eget livs pyramide, samtidig som dette fjerde kastet lar ham falle med et plask midt i Nemisjøen ${ }^{11}$. For, som vi vet, hybris rammes alltid av gudenes Nemesis.

Selvsagt er det Sigrid, navnesøster av sveadronningen som avslo Olav Tryggvasons frieri ${ }^{12}$, som er årsak til at Malm handler slik, prisgitt et øyeblikk av galskap som han straks fortrenger. Bortreist med foreldrene har hun nemlig i Napoli latt seg offentlig forlove med den sleipe Dahlqvist, stikk i strid med den hemmelige forlovelse hun inngikk med Malm før familiens avreise. Dette kommer ikke som noen overraskelse på leseren. Den Gamle så nemlig en slange krumme seg i hennes smilende munnviker første gang han så henne, og denne «Snogen» (134) stakk også sin hale frem da hun fikk høre av faren at Psyke har hans datters ansikt.

Det den Gamle antyder, er at Sigrid ser sitt eget vakre ansikt avspeilet i Malms modellering av Psykes fysiognomi. Og i et langt brev som moren hennes har skrevet til Malm, men som den Gamle åpner og lenge holder for selv, blir hans skepsis grundig bekreftet. Moren må åpent bekjenne at det er forfengelighet (en dødssynd) som er den styrende drivkraft hos datteren. Hun er en slags kvinnelig Narkissos. Hun har latt Malm gi henne en strålende selfie, som med Malms stigende berømmelse også vil gi henne en «evig» plass på kunstens himmel. Men når hennes andre beiler, Dahlqvist, brått arver en stor formue etter sin mor, ser hun ham som en Krøsus og altså en langt tryggere skikkelse å knyttet sin skjebne til.

For Malm framstår livet selvsagt som tømt og meningsløst etter at hans Sigrid har sviktet. Han flytter over til et knøttlite rom og gjør ingen egne forsøk på å skape kunst, men overlever så vidt ved å flikke litt på andre kunstneres gipsfigurer. Ofte er han på ensomme turer i skog og fjell utenfor Roma. En høstkveld treffer den Gamle på ham ved Nemisjøen. Plutselig lyder et måkeskrik, og Malm hvisker for-

${ }^{11}$ Ifølge Gammeldansk Ordbog betød ordet kav «dypt vann», men ordet er ikke lenger i bruk.

${ }^{12}$ Ifølge sagaen om Olav Tryggvason i Snorres Heimskringla ble Sigrid Storråde især kjent for å utløst et utbrudd av raseri hos Olav da han fridde til henne. Hun spådde hans undergang. 
ferdet: «Hørte du, det var Huldrens Stemme der klang. Husker du Guldstenene? Tre Guldstene kunde jeg kaste over Søen. Tre, o min Gud, ikke flere!» (145).

Men denne høsten oppsøker han ofte også et kloster og en klosterbror. Og en kveld i november dukker han opp hos den Gamle, dyvåt, likblek, i et dundrende tordenvær. Morgenen etter strømmer Tiberen over sine bredder. En ny slags Malm, glødende av energi, vekker opp sin venn og varsler om at byens jødiske ghetto holder på å bli satt under vann. De to blir vitne til et drama der jøder skylles vekk fra sine fattigslige hjem og ned i elva, ledsaget av hånende utrop fra lokale romere. Malm reagerer motsatt. Han står som en Herakles-skikkelse, rank og rett, og kaster seg til sist ut i elva for å redde en gammel, jødisk kvinne. Hun berges opp på land, men en kaskade av løsrevne tømmerbjelker river ham med seg og han forsvinner. «Saaledes endte Malm», sier den Gamle. «Faa kjendte ham, Færre forstod ham, og kun jeg begræd ham» (154).

\section{Martyr - men for hva?}

Ja, men hva døde han for? Flere av de lærde som har kommentert boka, mener at Bergsøe opprinnelig ville la den Gamle få det siste ordet og siden på kunstig vis hektet epistelen om ham inn i hovedhistorien om Henrik Vernon ${ }^{13}$. Selv synes jeg at historien om Olaf Malm står godt på egne føtter, like godt som fortellingen om Amor og Psyke i Lucius Apuleius: Det gyldne esel ${ }^{14}$. Men mye står åpent her. Leseren kan lese den gjennom egne brilleglass, farget av samtida. Han kan vurdere hva Bergsøe selv kan ha ment før han lot Malm gjenoppstå som klosterbror til sist i boka. Eller han kan lytte til hva den Gamle selv ville si med historien om telemarkingen og hans tragiske slutt.

Jeg tror Bergsøe deler perspektivet til den gamle. Han mener at Malm med større rett enn John Keats kunne fortjene disse ord på sitt gravmæle på den protestantiske kirkegård: «Her hviler Een, som paa Grund af sine Fjenders krænkende Had og Livets uforsonlige Bitterhed ønsker disse Ord indgravede paa sin Liigsten: «Herunder slumrer Een, hvis Navn er skrevet paa Bølgen» (154). Malm dør som martyr for den evige kunst. I alle sine tre verk, sine tre kast, maktet han å blåse liv

${ }^{13}$ Blant dem er Flemming Conrad og Lars Peter Rømhild som i sitt «Efterskrift» til nyutgivelsen av Fra Piazza del Poplo, Novelle-Cyclus 1-3 (1988) framhever at «Malms Historie» fremstår som selvgyldigt, afrundet og afsluttet» og at «den er ført frem til sin Konklusion (...) med Malms druknedød i Tiberen» (s. 556). Også P.V. Rubow (jf. note 1 og 3) mener at «Malms Historie» lukkker seg selv og at «det er høyst usandsynligt at Malm oprindelig har været ment som Henrys fader (s. 15).

${ }^{14}$ Det gyldne esel (skrevet sent på 100-tallet) er regnet som den eneste roman som har overlevet i sin helhet siden romertiden. Den har en rammefortelling og en rekke små og store bifortellinger. Den lengste er historien om Amor og Psyke. 
inn i død materie, slik universets skaper har fylt jorda med et bølgende liv som ustanselig fornyer seg selv. Alt det skapte, det uendelig foranderlige, er verdt omsorg, studium og en innsats på liv og død. Dette blir stadfestet av Malm også når han redder den gamle kvinnen. Likeså av den Gamles egen fortelling og av forfatter Bergsøe selv slik han lar den komme på trykk i Fra Piazza del Popolo.

At han lar en staut, ulærd nordmann vise seg verdig til å bære videre arven fra den antikke kunst, er vel også i logisk samsvar med kunstidealer som rådet langt inn på 1800-tallet. Især den ville, ubebodde natur var stedet som åpnet mot det sublime, det opphøyde. Det var ikke minst ved sine opphold i Roma at norske malere som Thomas Fearnley og I.C. Dahl fikk blikk for det opphøyde og storslåtte i norske fjell og fossevell. Tilsvarende kan en unggutt som er vokst opp omgitt av utøylet natur, raskt ha tilegnet seg skjønnheten i antikk skulptur, f.eks. diskoskasteren til grekeren Myron. Hans egen kropp har utstrålt noe av den samme kraft, ferdighet og harmoni som denne skulpturen ${ }^{15}$.

Viktig for inntrykket av sammensmelting mellom det antikke og det erkenorske er vel også Bergsøes håndtering av ulike typer fortellinger som var i omløp lenge før romansjangeren slo igjennom. Det kan være legender, myter, sagn, eventyr og fabler, mer eller mindre med feste i noe mytologisk, noe historisk eller noe selvopplevd. Den Gamles historier om et sunket palass av gull i Nemisjøen er tydelig bygget på gresk-romerske sagn fra Roma-egnen med røtter i keiserveldet. Den slags historier er narratologisk klart i slekt med Per Christian Asbjørnsens Norske Huldre-Eventyr og Folkesagn (1845-1848), et arsenal for den type folketro som Malm blir offer for i drømmen om Huldra. Men samtidig er skikkelsen Olaf Malm holdt innenfor et realistisk konsept. Han er den han er, seg selv lik, uten staffasje. Som en del av en «dokumentarisk belysning» av Bergsøes roman, gjengir Peter Hermann Rohde et møte mellom Henrik Ibsen og Bergsøe i Roma like etter at boka kom ut. Der sier Ibsen: «Jeg ser at Deres nye roman er skrevet efter Virkeligheden; det er vi tvungne til nu om Stunder - de smægtende Romanheltes Tid er forbi» ${ }^{16}$.

Litt spiller vel også «Malms Historie» på norske kongesagaer, jf. varselet Malm får ved Nemisjøen når muskelsener slites over i et øyeblikk av overmot. Her fins ekko både i Bergsøes egen tekst - jf. scenen i opptakten til den gamles fortelling: «hva brast så høyt?», og dermed også i Snorres saga om Olav Tryggvason. Men noe som ikke siden slites over, er de sterke bånd som her blir knyttet mellom to unge menn fra det gamle tvillingriket Danmark-Norge. Og billed-

\footnotetext{
${ }^{15}$ Diskoskasteren er ikke bevart i original, men to av de beste kopiene finnes i dag i Nasjonalmuseet i Roma, hogd ut i marmor. Der var de tilgjengelige også på den tida billedhogger Bertel Thorvaldsen arbeidet i Roma (1797-1837).

${ }^{16}$ Hermann P. Rohde (1972): Digt og Sandhed om en berømt roman. Piazza del Popolo i dokumentariske belysning, s. 18. Se nærmere opplysninger på litteraturlista.
} 
hogger Thorvaldsen, i Roma selve garantisten for en link mellom klassisk billedhoggerkunst og det nordiske, vokste opp på Island og er av samme, norrøne malm som unggutten fra Telemark. Det samme gjelder på ingen måte den sleske svensken Dahlqvist.

Men selv om historien om Malm først og fremst er om en person som oppfyller sitt kall som kunster, og som gjennom den Gamles framstilling gjør leseren klok på hva kunstnerisk storhet innebærer, så er den religiøse dimensjonen på ingen måte fraværende. Som jeg har antydet tidligere, peker Malms suksessive bruk av leire, gips og marmor klart mot stadiene Jesus må gjennomgå for å fullføre sin misjon som Guds sønn og menneskenes frelser. Og som Paul Rubow påpeker i sin bok om Bergsøes roman, er det en mulig kopling mellom Malms historie og helten i Hans Christian Andersens eventyr Psychen, et eventyr i en samling Andersen utga i 1862 - merk årstallet! (Rubow 1948: 36-38) ) $^{17}$

Den er om en ung, fattig og selvkritisk kunster som fra gaten får se en deilig, lettbent pike sveve forbi i en hage, datteren til en rik fyrste. Han går hjem, gir henne skikkelse i leire, etterhvert også i marmor. Statuen kaller han Min Psyche, altså ikke Psyche slik hun nettopp er malt av Rafael på en fresko i Vatikanet. Når statuen er ferdig, blir den lovprist av vennene hans, og så oppsøker han slottet der piken bor for å fortelle henne om det ferdige kunstverket. Men alene synet av den skjønne setter ham i fyr og flamme og han begår straks et heftig frieri. Hun blir rasende og roper «Afsindige!», sagde hun, «Bort! ned!» og hun vendte ham ryggen» (Andersen 1966: 109).

Med dette har hun knust ham som kunstner, han begraver statuen i en brønn med en kort gravtale: «bort, ned!» og lever siden som munk i et kloster. År og århundrer går og et nonnekloster blir satt opp nær den brønnen der statuen ble gravd ned. En dag blir den funnet, og opp løfter man en psykeskikkelse med vinger: «Hvor er den deilig! Fuldendt, et Konstværk fra den bedste Tid» (118), sier de som er vitner til denne hendelsen i Andersens eventyr.

I Bergsøes versjon av et knust kunstnerliv er det også en kvinne som frigjør kunstnerens skapende krefter, og også hos Bergsøe blir hun årsak til hans skjebneforlis. Selv tenker Andersens gamle klosterbror like før han dør at aldri vil hans Psyche, hans beste «Livsblink» (116), oppstå av graven. Men eventyret lar ham altså ta feil, hans liv har ikke vært forgjeves. En liknende reinkarnasjon av Malms vakre Psyke er ikke mulig i Bergsøes fortelling. Men slik vi som lesere får møte både dette verket og Malms to andre lykkekast i den Gamles fortelling, mener jeg at Bergsøe med fiksjonens kraft har sikret karakteren Malm et fortsatt liv innenfor litteraturens verden.

${ }^{17}$ Eventyret utkom som ett av fire eventyr i samlingen Nye Eventyr og Historier af H.C. Andersen på C.A. Reitzels Forlag, Kbh. i november 1861, men med 1862 som utgivelsesår. Andersen var i Roma i april og mai 1861. 
Det virker litt skjevt å la ham gjenoppstå som ærverdig klosterabbed i romanens tredje hoveddel ${ }^{18}$. Langt bedre er det at Bergsøe på slutten av den Gamles fortelling lar ham opptre med fornyet livskraft, så å si med helnorsk signatur. Tiberen buldrer og bruser, allting kastes rundt og drives både nedstrøms og motstrøms. Men Malm, som vokste opp på en gård høyt oppe ved et fossefall, kan kyndig tolke elvas bevegelser og bruke sin norske innsikt til å berge et menneskeliv. Og Bergsøe gir ham en verdig litterær gravskrift, både som kunstner og menneske.

Som nevnt i innledningen, var kunstfeltet i Europa inne i en brytningstid da Bergsøe publiserte denne boka. Det han lykkes med i Historien om Olaf Malm, er en legering mellom det harmonisk avbalanserte i sansen for klassisistisk skulptur og det eruptivt erkenasjonale. Begge deler syntes å inngå i en tilsynelatende uhellig allianse i den tragiske historien om Malms skjebne. Men slik Den gamle/Bergsøe framstiller livsløpet hans, framgår det tydelig at det kosmopolitisk universelle kan smelte sammen i en vakker syntese med det rotfestet nasjonale/lokale ${ }^{19}$.

Menneskers avmakt i møter med lunefulle naturkrefter, det være seg kolera eller en voldsom oversvømmelse, antyder at Malms historie - i samsvar med andre av bokas livsbilder - åpner for tilnærming til en realistisk skrivemåte. Det innebærer ikke at den religiøse dimensjonen er fraværende. Tvert imot; den er helt sentral. Parallellen mellom Andersens Psychen der et sant kunstverk gjenoppstår for øynene av et publikum som skal begrave en nonne, er klar. Det er den Gamles kunstferdige beretning som litterært sett sikrer gjenoppstandelsen av Olaf Malms tre kunstverk og som udødeliggjør ham innenfor fortellingens estetiske univers. Og med denne historien har også Vilhelm Bergsøe fortjent varig nimbus som skaper av sann kunst.

\footnotetext{
${ }^{18}$ Der dukker han nemlig opp (jf. s. 10) som «Fader Ambrosius» med langt virke bak seg ikke bare som katolsk prest, men også som dyktig kunsthåndverker viet til utsmykning av religiøse klenodier.

${ }^{19}$ En slik to-sidig basis for fornyelse av kunst omtales av redaktør Bettina Baumgärtel i det inneledende kapitlet i boka The Düffeldorf School of Painting and its International Influence 1819-1918: «The question can be raised as to whether art perhaps actually comes into beingin the dialectical interplay between cultural rootedness and cosmopolitan freedom» (s. 18).
} 
Litteratur

Andersen, H.Chr. (1966). Samlede eventyr og historier. B. 3. Oslo: Gyldendal Norsk Forlag. Asbjørnsen, P.Chr. (1845-1848). Norske Huldre-Eventyr og Folkesagn, Første Samling og (1848) Anden Samling. København: Gyldendalske Boghandels Forlag.

Ask, O.A. (1996). Rom - pladsernes by: 40 pladser og deres sevordigheder. Københanvn: Thaning \& Appel.

Baumgärtel, B. (red.). (2011). The Düsseldorf School of Painting and Its International Influence 1819-1918. Düsseldorf: Michael Imhof Verlag.

Bergsøe, V. (1877 [1867]). Fra Piazza del Popolo. Livsbilleder, samlede i Rom. Faksimilie av 4. utgave med undertittel Novelle-Cyklus af Vilhelm Bergsøe. København: Gyldendal.

Bergsøe, V. (1988). Fra Piazza del Popolo. Novelle-Cyclus 1-3. Utgitt i serien Danske Klassikere 1988. Tekstudgivelse, noter og efterskrift ved Flemming Conrad og Lars Peter Røhmild. København: Borgen.

Lie, J. (1920-1921). Samlede Digterverker, Standardutgave. Her: bd. X. Kristiania: Aschehoug Forlag.

Rohde, H.P. (1972). Digt og Sandhed om en berømt roman. Piazza del Popolo i dokumentariske belysning. Bind 19 i serien Fund og forskning i Det Kongelige Biblioteks samlinger. Kan lastes ned fra: https://tidsskrift.dk/index.php/fundogforskning/article/view/1813/3069 [lesedato: 15.05 .2018$]$.

Rubow, P.V. (1948). Vilhelm Bergsøe og hans store roman. København: Gyldendal.

Støylen, B. (1899). Norske Barnerim og Leikar. Kristiania: Aschehoug \& Co. 